\title{
Article
}

\section{Bibliometric Analysis of Dental Erosion (2011-2020)}

\author{
Laura Marqués Martínez $\mathbb{1}$, Carla Borrell García *, Clara Guinot Barona $\mathbb{1}$, Paula Boo Gordillo \\ and Esther García Miralles
}

check for updates

Citation: Marqués Martínez, L.; Borrell García, C.; Guinot Barona, C.; Boo Gordillo, P.; García Miralles, E. Bibliometric Analysis of Dental Erosion (2011-2020). Appl. Sci. 2021, 11, 10971. https://doi.org/10.3390/ app112210971

Academic Editor: Gaspare Palaia

Received: 20 October 2021

Accepted: 15 November 2021

Published: 19 November 2021

Publisher's Note: MDPI stays neutral with regard to jurisdictional claims in published maps and institutional affiliations.

Copyright: (c) 2021 by the authors. Licensee MDPI, Basel, Switzerland. This article is an open access article distributed under the terms and conditions of the Creative Commons Attribution (CC BY) license (https:/ / creativecommons.org/licenses/by/ $4.0 /)$.
Faculty of Medicine and Health Sciences, Catholic University of Valencia, 46001 Valencia, Spain; laura.marques@ucv.es (L.M.M.); clara.guinot@ucv.es (C.G.B.); paula.boo@ucv.es (P.B.G.); esther.garcia@ucv.es (E.G.M.)

* Correspondence: carla.borrell@ucv.es

\begin{abstract}
During the past decade, an increase in the number of studies about dental erosion has been observed. The aim of the present study was to describe the current trends in published scientific articles related to dental erosion between 2011 and 2020. Data of the authors, year and language of publication were analyzed. A bibliometric analysis of the articles published in PubMed was conducted using the MeSH terms (dental erosion) and (tooth erosion) using the Boolean operator OR/AND. A sample of $n=1090$ articles published during the past ten years (2011-2020) was obtained. The variables analyzed were the language of the article, the year of publishing, the number of authors, the affiliations of the first and last author and the relationship between them. The countries of origin of the first and last author were ranked according to the number of publications, led by Brazil, the UK, and the USA. During the analysis of the type of article, we observed that $79.4 \%$ of all publications were research articles. In recent years, a significant increase in research articles on dental erosion has been observed, especially in Brazil and the UK, with a high number of publications of translational articles in humans and cross-sectional observational studies. The main findings in this article will help researchers, academics and students to characterize scientific results regarding dental erosion, to evaluate management strategies and to identify important topics and issues that will help design future research.
\end{abstract}

Keywords: bibliometric; citation analysis; altmetric; dental erosion; tooth erosion

\section{Introduction}

Dental alterations involving the loss of the dental structure are not new diseases. These kinds of lesions can be found in archaeological human remains. During the past decade, a considerable increase in alterations involving the loss of the dental structure due to non-carious diseases has been registered [1].

The term "tooth wear" involves a group of diseases of different etiology, which traditionally are attrition, abrasion, abfraction and erosion. Since the etiological factor is rarely identified, once the problem has been diagnosed, a detailed anamnesis that registers every medical record would be essential in order to implement the appropriate preventive measures for every case [2-5].

In dentistry, the clinical term dental erosion is defined as the pathological, chronical, localized and painless loss of the dental tissues caused by the chemical action of acids without any involvement of bacteria [1,4-10].

The acids that cause this dental structure dissolution by direct contact may arrive at the oral cavity from different sources. These include intrinsic sources such as the hydrochloric acid that comes from the stomach, which dissolves the enamel due to its low $\mathrm{pH}$ (around 1). This is common in patients who suffer from gastroesophageal reflux, regurgitations and persistent vomiting, and especially among patients who present eating disorders such as anorexia or bulimia [2,4,7-9,11-15]. The acids may also come from extrinsic sources, such as exogenous acids from the consumption of liquid or solid foods such as fruits, fruit juices 
and carbonated drinks. These acids may also come from acidic medications such as ascorbic acid (vitamin C) or acetylsalicylic acid $\left(\right.$ Aspirin $\left.{ }^{\circledR}\right)[2,4,6-9,16]$. As a third source, unknown acids may come from idiopathic sources. In these cases, the clinical exploration, anamnesis, and complementary tests do not allow the etiology of the lesions to be clarified $[4,13]$.

For decades, dental erosion has remained a condition of minor interest for public and private clinicians, and for the scientific community [17]. However, during the past decade, a significant increase in the prevalence of erosion has been registered, especially among children and adolescents, which has led to a larger interest in the study and investigation of this condition by different sanitary disciplines, especially dentistry [1].

The World Health Organization (WHO) is the authority which addresses and coordinates all sanitary action that takes place in the United Nations [18]. It is its responsibility to schedule and coordinate every investigation on health, and to set the norms that must be followed by the public health institutions worldwide. In 2008, the WHO presented an Action Plan for the Global Strategy for the Prevention and Control of Noncommunicable Diseases with the objective of promoting actions to reduce the main risk factors of nontransmissible diseases such as dental erosion. In 2003, five years before the launch of the previously mentioned strategic plan [19], the WHO considered the promotion of oral health and analyzed the risk factors of dental diseases in its World Oral Health Report. Educating the population was established as the main strategy for the prevention and control of these diseases. Different strategies were proposed [20]:

- Nutritional counseling covering both general aspects of health and nutrition and specific aspects about oral health.

- Information about the benefits of reducing the intake of carbonated sweetened drinks since it is an important risk factor in the development of dental erosion.

- Advising about the benefits of reducing the intake, the amount and the frequency of acidic and carbonated drinks, since it is the main risk factor in the development of dental erosion.

At present, the world is facing important challenges related to nutrition, either by its deficit which causes hunger or nutritional deficiencies, or by its excess, causing overweight and obesity. The globalization of the markets and the economic development have led to rapid changes in diets and lifestyles, increasing the prevalence of chronic diseases such as obesity, diabetes, cardiovascular diseases, cancer and osteoporosis, and oral diseases such as caries, periodontal disease and dental erosion [20,21].

The WHO created the International Statistical Classification of Diseases and Related Health Problems (ICD) in 1998 to enable the classification of diseases in order to keep a systematic recording system, allowing the interpretation and comparation of data about mortality and morbidity from different countries or regions and during different periods of time. The term "dental erosion" appeared for the first time in this classification in 2010, twelve years after its coining [22].

It is important to highlight that in the past decade, an upward trend in the number of studies about dental erosion has been observed, as shown in Figure 1. The figure represents the number of articles published about this topic from 1945 to the present. During the first decades, until around 1960, very few studies were conducted-less than 30 per year. During the 1990s, an increase in scientific production can be observed, with an average of 50-70 articles published per year. As previously stated, it was during the twenty-first century, as the prevalence of dental erosion was increasing, that researchers were motivated to increase the number of publications, reaching up to 250 per year in recent years. 


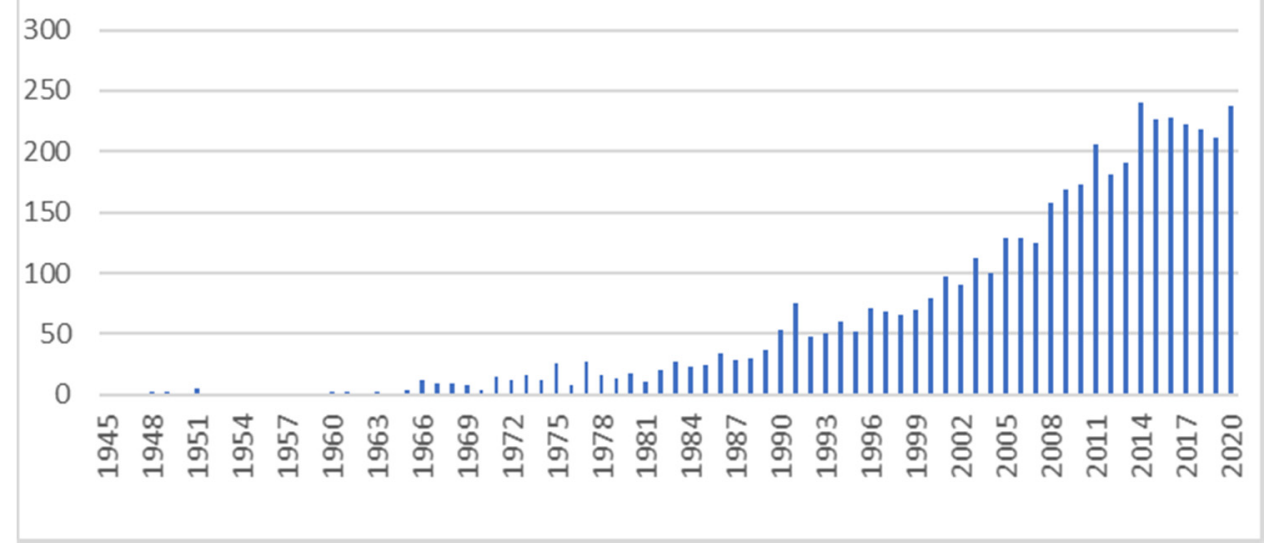

Figure 1. Number of articles related to dental erosion published in PubMed per year since 1945 to the present time.

However, despite the massive quantity of scientific articles about dental erosion, there is a lack of bibliometric studies that make it possible to evaluate the evolution of the disease. Therefore, the main objective of this study was to describe the current trends in the articles related with dental erosion during the period 2011-2020, analyzing the year of publication, the language and different data about the authors through a bibliometric analysis.

\section{Materials and Methods}

\subsection{Research Strategy}

A bibliometric analysis of the articles published in PubMed was conducted using the $\mathrm{MeSH}$ terms (dental erosion) and (tooth erosion) with Boolean operators OR/AND in the advanced search tool: "tooth erosion" [All Fields] OR "dental erosion" [All Fields] OR ("tooth" [All Fields] AND "erosion" [All Fields]) OR ("dental" [All Fields] AND "erosion" [All Fields]). The search was limited to the past 10 years (2011 to 2020) and there was no limitation of language. The search was performed on 20 April 2021 and a total of 1894 articles were obtained. The articles were exported to PDF and two authors (LM and EG) performed an independent manual revision using the abstract and, if necessary, the complete text of the article.

\subsection{Data Collection/Data Analysis}

Each item was examined according to the following including criteria: (a) items related to dentistry; (b) original articles, reviews, series of cases and guidelines; (c) articles published between 2011 and 2020. The exclusion criteria were: (a) items unrelated to dentistry; (b) articles without registered authors.

In the case of a lack of consensus about the selection of an article between two authors, a third author (CB) took the final decision. After an exhaustive selection process, 804 of the total of 1894 reviewed articles were eliminated according to the inclusion and exclusion criteria, ending with a final sample of 1090 articles (Figure 2). For each selected article, two sets of classification parameters were registered (parameters based on authors and parameters based on the article) and data were collected using an Excel spreadsheet (Microsoft Office for Mac 2011):

(1) Parameters based on the authors:

- Number of authors.

- Number of affiliations.

- Name of the first author, institution and gender.

- Name of the last author, institution and gender. 
- Geographical affiliation of the first and last author (all countries were classified by geographic area): (1) North America; (2) European Union (EU membership 2006); (3) European countries, non-member states (EU membership 2006); (4) Asia and Australia; (5) Central and South America and (6) Other countries. Norway and Switzerland were included in the EU member states.

- Relationships among authors: (1) local (all authors share the same center of affiliation), (2) national (all authors share the same country of affiliation) and (3) international (authors' affiliations belong to different countries).

(2) Parameters based on the title of the article:

- Language.

- Year of publication.

- Topic of the article (Table 1).

- Type of article: (1) basic articles; (2) translational studies in human, animal or theoretical studies; (3) randomized and non-randomized controlled clinical studies; (4) observational cohort studies, case-control studies, case series and transversal studies.

Table 1. Classification of the topics.

\begin{tabular}{cc}
\hline & TOPICS \\
\hline T1 & Prevalence \\
T2 & Saliva \\
T3 & Pard tissues \\
T4 & Soft tissues \\
T5 & Diet \\
T6 & Vomiting and regurgitation \\
T7 & Medications \\
T8 & Hygiene \\
T9 & Systemic diseases \\
T10 & Socioeconomic level \\
T11 & Diagnosis \\
T12 & Restorative treatment \\
T13 & Preventive treatment \\
T14 & Others \\
T15 &
\end{tabular}

Pubmed.
$(\mathrm{n}=1894)$
Inclusion/Exclusion criteria applied.
Records excluded by a human.

$$
(n=804)
$$

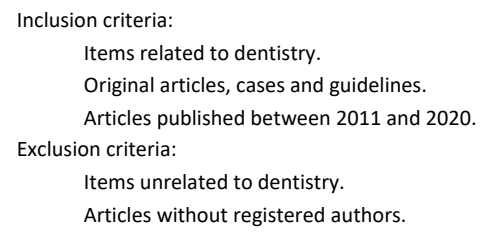

Figure 2. PRISMA flow diagram of article search and selection process. The literature search was conducted in April 2021.

If the type of study was not evident in the title or abstract of the article, the complete text was analyzed and the type of study was identified using a decision tree [23].

\subsection{Statistical Analysis}

A descriptive analysis of the absolute and relative frequencies was carried out for categorical variables. Statistical mean, median, standard deviation and range for the 
quantitative variables (number of authors and affiliations) were analyzed both simple and crossover by the country of the first author and year of publication of the article.

Due to the exhaustive selection of the articles, the working sample corresponded exactly to the total population, so inferential analysis would be meaningless.

\section{Results}

\subsection{Parameters Based on the Authors}

The sample for the investigation consisted of 1090 articles. Regarding the gender of the authors, a slight dominance of articles signed by women was observed (54.4\%). This percentage progressively increased throughout the decade (21 percentage points more in 2021 compared to 2020). The trend was generally the opposite for the case of the last author being male (57.2\%), but the percentage decreased more moderately over time (15\%). Women showed an evident predominance over men both as first and last authors in South America, especially in Brazil.

The average number of authors per article was $4.7 \pm 2.1$, with a difference in the South American area that exceeded the general average by one point (5.7). A total of $52.2 \%$ of the articles were signed by five or more authors, increasing from 4.2 in 2011 to 5.6 in 2020. The analysis of the relationship between the authors showed that $63 \%$ shared a center of affiliation (local), 20.3\% were from the same country (national) and only 16.7\% were from different countries (international). Regarding the relationships between authors over the course of the 10 year study period, the process of globalization was clearly manifested in the reduction in the relative weight of the local sphere. The number of affiliations of the first author was one in $97.7 \%$ of the articles. In the case of the second author, the rate was very similar: $97.2 \%$. Figure 3 shows the ranking of countries of origin of the first and last authors according to the number of publications, led by Brazil, the UK, and the USA, and shows a distribution dominated by the EU (41.5\%) and Central-South America (27.3\%). The large increase in Brazilian articles during the decade in terms of the number of articles is very noteworthy. Note that in 2011, Brazilian articles represented a similar percentage to that of the UK or the USA, but in 2020 the advantage was considerable, reaching $32.6 \%$ of articles published (Figure 4).

\section{Publications by country}

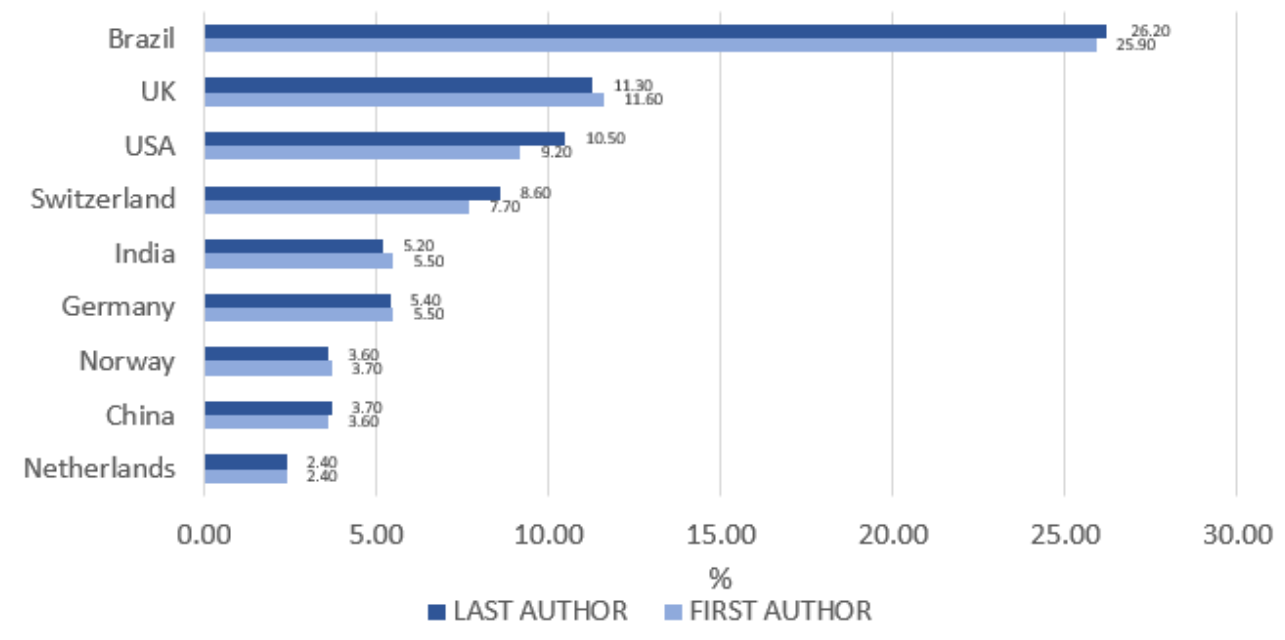

Figure 3. Origin of affiliation of the published articles. 


\section{Evolution of provenance by country}

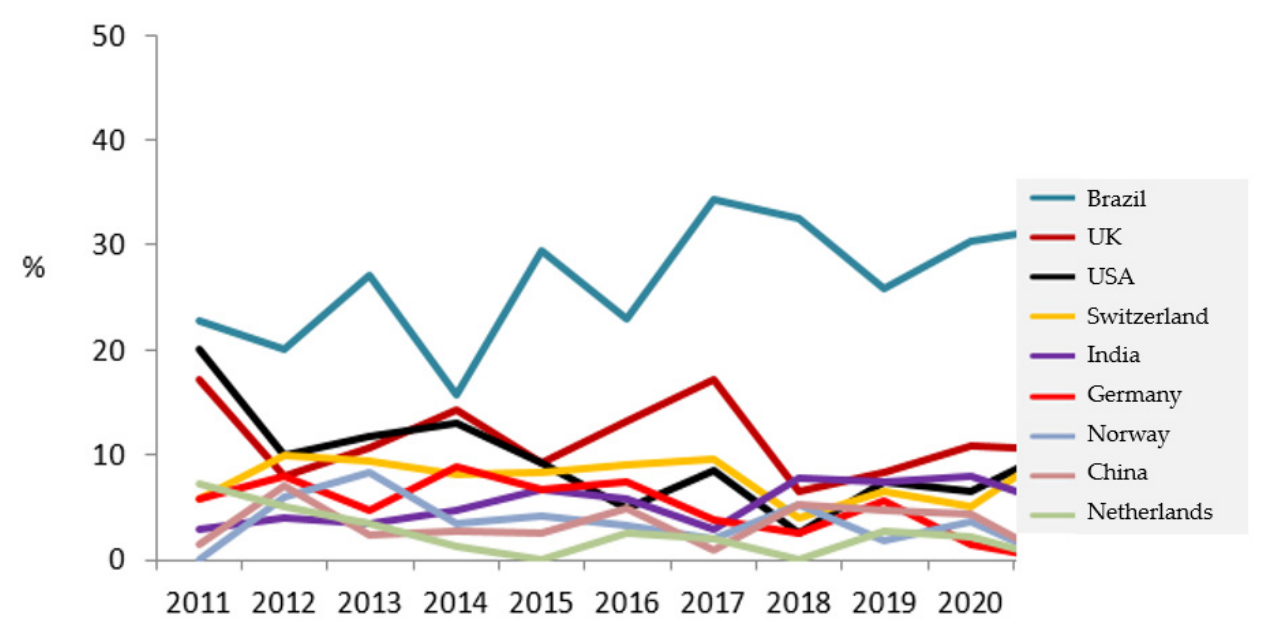

Figure 4. Origin of the articles published during the 10 years of the studied period.

\subsection{Parameters Based on the Title of the Article}

The sample for this investigation consisted of 1090 articles published in more than 200 different journals. English was the language of publication in $97.2 \%$ of the articles. The relative weight of each year of the period regarding the proportion of the articles over the total was variable, between $6 \%$ in 2011 and $13 \%$ in 2014 .

When analyzing the type of article, we observed that $79.4 \%$ of all publications were research articles. Figure 5 describes in detail the different designs of the items in the sample.

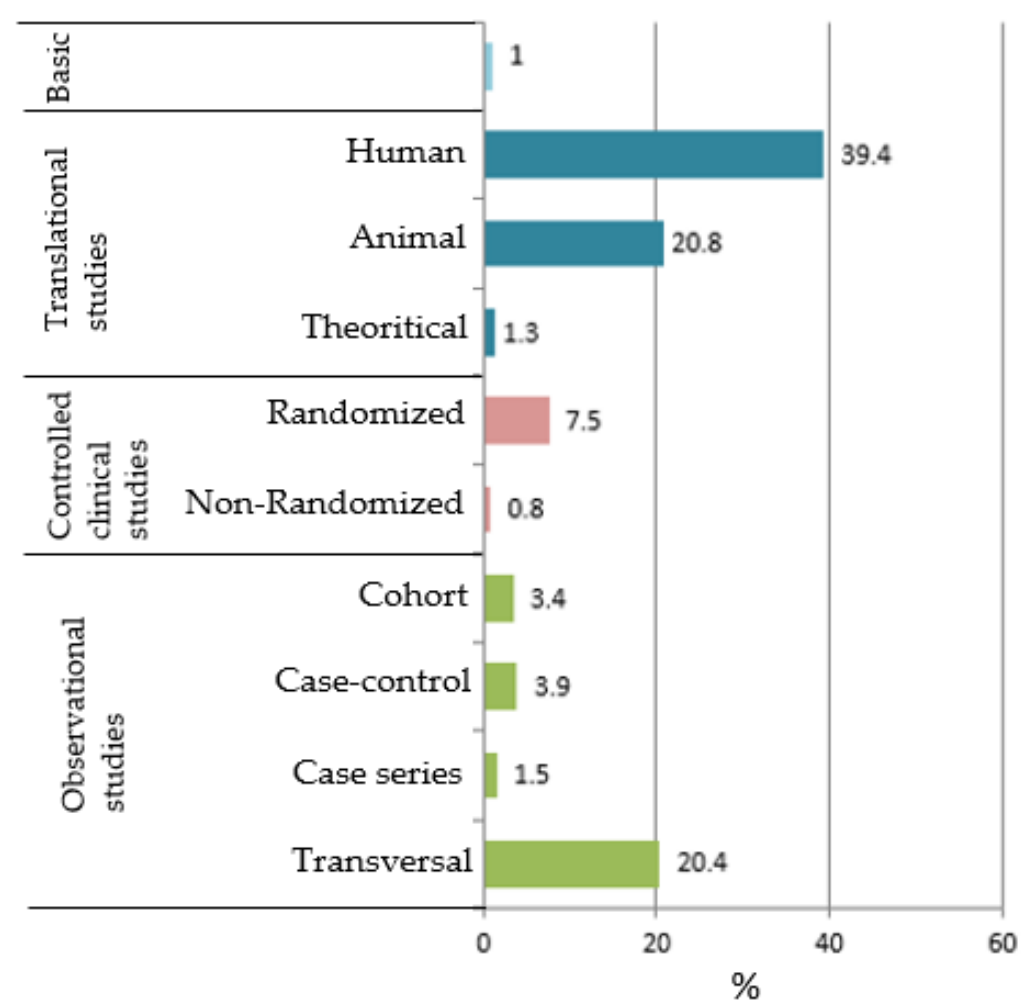

Figure 5. Distribution of article types.

Research articles showed a slightly upward trend over the last decade. At the beginning of the period, the important relative weight of systematic reviews and meta-analyses stands out. Two sub-periods were identified within the study decade, with 2016 as the cut- 
off point. Until that moment, translational articles gained importance while the prevalence of observational clinical articles was reduced, reaching their peak (45\%) around 2014-2016 in humans and those of animals in 2016-2017. From 2016 to 2020, the trend was reversed (Figure 6).

\section{Evolution of the different types of articles}

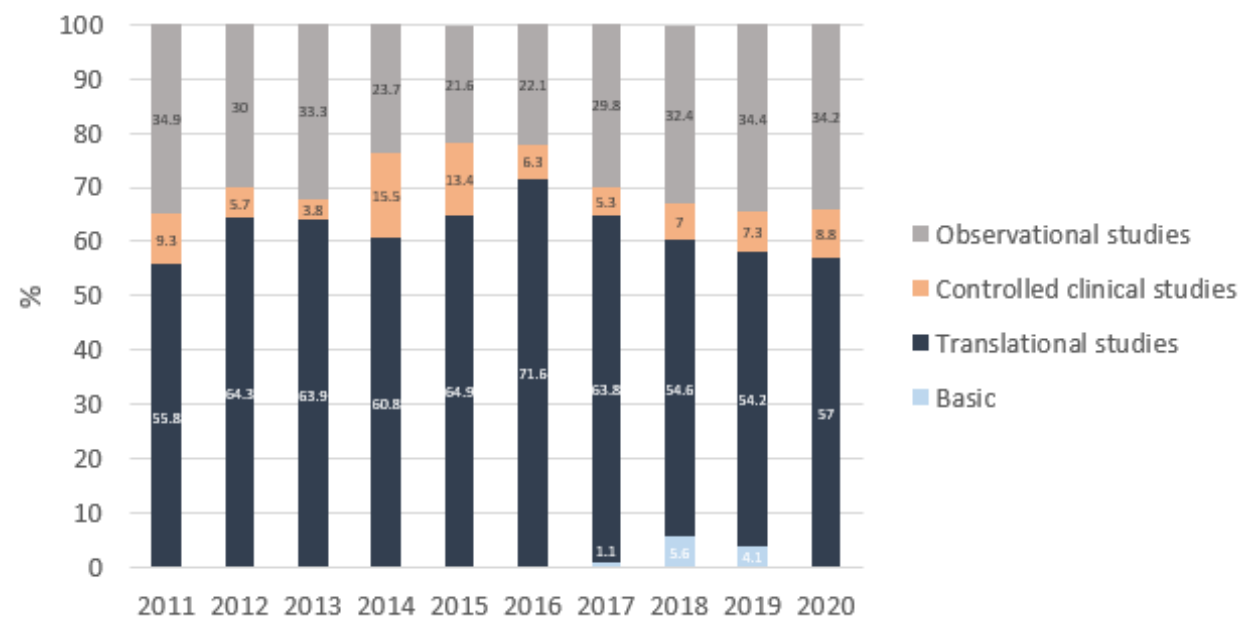

Figure 6. Evolution of the different types of articles during the 10 year period.

When analyzing the types of articles published, 79.4\% of them were research articles, with translational studies in humans being the most frequent, followed by crosssectional observational clinical studies. Regarding the geographical areas, it can be observed (Figure 7) that translational studies predominated in Central-South America (73.2\%), while in most areas clinical studies reached half of the total.

Types of articles regarding the geographical area

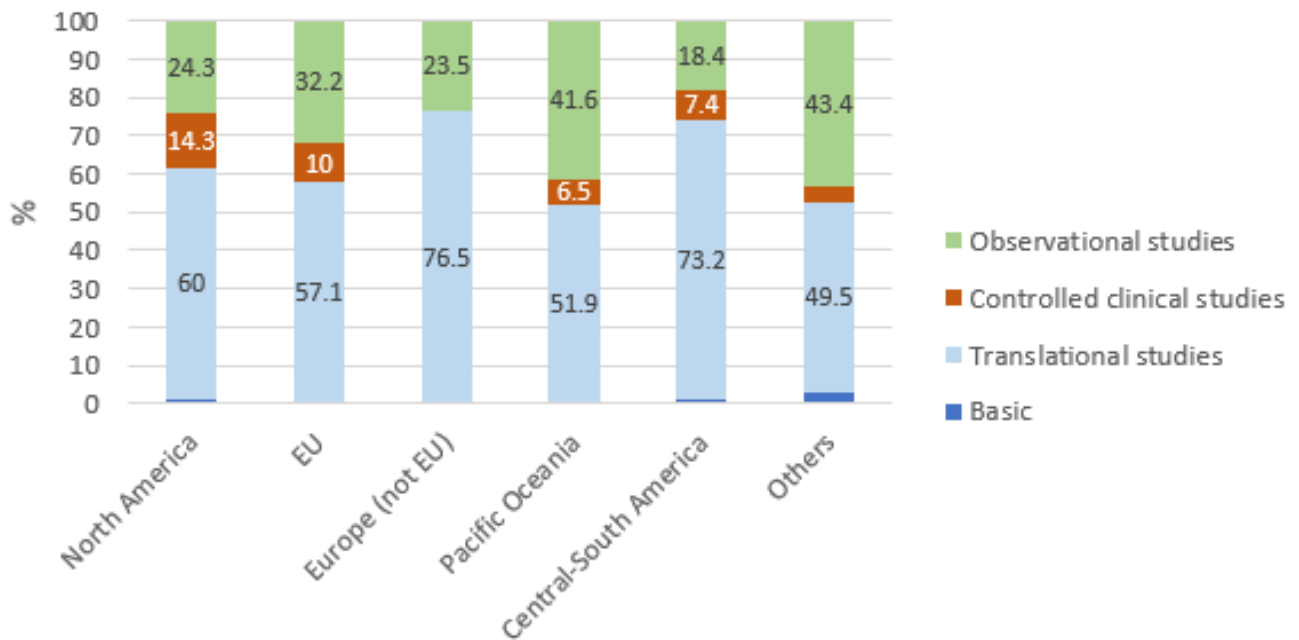

Figure 7. Distribution of the types of articles regarding the geographical area.

There were three outstanding topics: preventive treatments (27.6\%), diet (23.4\%) and hard tissues $(22.9 \%)$. Table 2 shows the distribution of the topics according to the geographic areas. A dominant trend in studies about prevention and diet in Central-South America was found, while in North America, the high percentage of studies about pathogenesis and clinical manifestations is noteworthy. 
Table 2. Distribution of the topics regarding the geographic areas.

\begin{tabular}{|c|c|c|c|c|c|c|c|c|c|c|c|c|c|c|}
\hline & \multicolumn{2}{|c|}{ Total } & \multicolumn{2}{|c|}{$\begin{array}{l}\text { North } \\
\text { America }\end{array}$} & \multicolumn{2}{|c|}{ EU } & \multicolumn{2}{|c|}{$\begin{array}{l}\text { Europe } \\
\text { (Not EU) }\end{array}$} & \multicolumn{2}{|c|}{$\begin{array}{l}\text { Pacific } \\
\text { Oceania }\end{array}$} & \multicolumn{2}{|c|}{ Other } & \multicolumn{2}{|c|}{$\begin{array}{c}\text { Central-South } \\
\text { America }\end{array}$} \\
\hline & $\mathbf{N}$ & $\%$ & $\mathbf{N}$ & $\%$ & $\mathbf{N}$ & $\%$ & $\mathbf{N}$ & $\%$ & $\mathbf{N}$ & $\%$ & $\mathbf{N}$ & $\%$ & $\mathbf{N}$ & $\%$ \\
\hline Total & 1090 & $100 \%$ & 104 & $100 \%$ & 452 & $100 \%$ & 18 & $100 \%$ & 101 & $100 \%$ & 117 & $100 \%$ & 298 & $100 \%$ \\
\hline Preventive treatment & 301 & $27.6 \%$ & 25 & $24 \%$ & 114 & $25.2 \%$ & 5 & $27.8 \%$ & 19 & $18.8 \%$ & 26 & $22.2 \%$ & 112 & $37.6 \%$ \\
\hline Diet & 255 & $23.4 \%$ & 21 & $20.2 \%$ & 102 & $22.6 \%$ & 7 & $38.9 \%$ & 32 & $31.7 \%$ & 35 & $29.9 \%$ & 58 & $19.5 \%$ \\
\hline Hard tissues & 250 & $22.9 \%$ & 14 & $13.5 \%$ & 90 & $19.9 \%$ & 5 & $27.8 \%$ & 17 & $16.8 \%$ & 30 & $25.6 \%$ & 94 & $31.5 \%$ \\
\hline Prevalence & 156 & $14.3 \%$ & 8 & $7.7 \%$ & 69 & $15.3 \%$ & 2 & $11.1 \%$ & 17 & $16.8 \%$ & 28 & $23.9 \%$ & 32 & $10.7 \%$ \\
\hline Restorative treatment & 121 & $11.1 \%$ & 10 & $9.6 \%$ & 51 & $11.3 \%$ & 1 & $5.6 \%$ & 13 & $12.9 \%$ & 12 & $10.3 \%$ & 34 & $11.4 \%$ \\
\hline Saliva & 112 & $10.3 \%$ & 11 & $10.6 \%$ & 53 & $11.7 \%$ & 1 & $5.6 \%$ & 5 & $5.0 \%$ & 9 & $7.7 \%$ & 33 & $11.1 \%$ \\
\hline Hygiene & 110 & $10.1 \%$ & 13 & $12.5 \%$ & 49 & $10.8 \%$ & 2 & $11.1 \%$ & 14 & $13.9 \%$ & 9 & $7.7 \%$ & 23 & $7.7 \%$ \\
\hline $\begin{array}{l}\text { Pathogenesis and clinical } \\
\text { manifestations }\end{array}$ & 84 & $7.7 \%$ & 16 & $15.4 \%$ & 45 & $10.0 \%$ & 1 & $5.6 \%$ & 7 & $6.9 \%$ & 6 & $5.1 \%$ & 9 & $3.0 \%$ \\
\hline Diagnosis & 71 & $6.5 \%$ & 7 & $6.7 \%$ & 47 & $10.4 \%$ & 1 & $5.6 \%$ & 4 & $4.0 \%$ & 4 & $3.4 \%$ & 8 & $2.75 \%$ \\
\hline Systemic diseases & 71 & $6.5 \%$ & 11 & $10.6 \%$ & 26 & $5.8 \%$ & 1 & $5.6 \%$ & 9 & $8.9 \%$ & 12 & $10.3 \%$ & 12 & $4.0 \%$ \\
\hline Vomiting and regurgitation & 55 & $5.0 \%$ & 9 & $8.7 \%$ & 26 & $5.8 \%$ & 0 & $0.0 \%$ & 7 & $6.9 \%$ & 6 & $5.1 \%$ & 7 & $2.3 \%$ \\
\hline Medications & 45 & $4.1 \%$ & 3 & $2.9 \%$ & 16 & $3.5 \%$ & 1 & $5.6 \%$ & 1 & $1.0 \%$ & 11 & $9.4 \%$ & 13 & $4.4 \%$ \\
\hline Socioeconomic level & 18 & $1.7 \%$ & 0 & $0.0 \%$ & 7 & $1.5 \%$ & 0 & $0.0 \%$ & 4 & $4.0 \%$ & 3 & $2.6 \%$ & 4 & $1.3 \%$ \\
\hline Soft tissues & 3 & $0.3 \%$ & 0 & $0.0 \%$ & 3 & $0.7 \%$ & 0 & $0.0 \%$ & 0 & $0.0 \%$ & 0 & $0,0 \%$ & 0 & $0.0 \%$ \\
\hline
\end{tabular}

\section{Discussion}

There is a consensus amongst the scientific community regarding the increase in the prevalence of dental erosion. In recent investigations, a high prevalence of lesions that affect enamel and dentin can be observed, with percentages that vary between 30 and $90 \%$, while lesions that affect the pulp are scarce [7,24-28]. This has generated an interest in the in-depth study of this disease in recent years, and led us to carry out this study in order to describe the profile of research articles related to dental erosion in the period 2011-2020, analyzing the year, language of publication and data of the authors. As far as we know, this is the first publication that analyzes the characteristics of articles related to dental erosion.

The bibliometric analysis consists of the application of mathematical formulas and statistical analysis in order to analyze the flow of documents and their bibliographic characteristics, evaluating the information of the authors, identifying the countries with the most scientific production as well as the topics and types of articles to optimize the information received by the scientists and to improve the organization and management of science [29].

\subsection{Parameters Based on the Authors}

In the present study, we observed that in most of the studied articles the authors belonged to the same institution, with few international collaborations. However, when analyzing each of the 10 years individually, a reduction in the relative weight of the local sphere was observed. This trend was observed in the study of Poskevicius, L. et al., where the collaboration in the publication authors from Estonia, Latvia and Lithuania with authors from Finland, Sweden and the United States was analyzed [30]. In the globalized world in which we live, new technologies and programs that encourage stays abroad favor the establishment of relationships between institutions in different parts of the world.

Patil, S. et al., in their bibliometric analysis on early childhood caries, observed that the greatest scientific production comes from the United States [31]. Other authors support these results, observing a greater scientific production from the USA, followed by Europe [32]. However, according to the ranking in the present study, the countries with the most publications on dental erosion are Brazil, the UK and the USA, showing a dominancy of the EU (41.5\%) in first place due to the publication of articles in the UK, Switzerland, Germany, Norway and the Netherlands, with Central-South America in second place $(27.3 \%)$.

When analyzing the gender of the first author, articles signed by female researchers predominated slightly; regarding the gender of the last author, the predominance was for men. However, in both cases there was an upward trend in women as the years progressed. 
These results are supported by other studies, such as the research carried out by AuraTormo, J.I. et al. [33]. This tendency may be a consequence of the increase in women studying dentistry, increasing from a fifth of all students in the 1980s to more than $50 \%$ today [34].

\subsection{Parameters Based on the Title of the Article}

Of the articles analyzed $(n=1090), 97.2 \%$ were written in English. It is estimated that $98 \%$ of the scientific results published today are in English, regardless of the country where the research was carried out. The main reasons are that the articles published in English have greater diffusion and acceptance in the scientific community, allowing the authors the opportunity to be referents in the international field [35].

When analyzing the articles published per year from 2011 to 2020, it can be observed that the years with the highest number of publications were 2014, 2020, 2016 and 2015, with a relative weight between $13.5 \%$ and $10.9 \%$, showing an increasing trend over the study period. This may be due to a greater awareness among researchers of the serious repercussions of dental erosion on the oral and general health of the world population [12]

Topics related to preventive treatments, diet and hard tissues were the most frequent in the sample (23-28\%). A progressive increase in the relevance of hard tissues was detected during the study period. When analyzing the topics of the articles, it is easy to understand why diet is one of the most published topics, as the increase in the intake of acidic drinks and foods is strongly linked to dental erosion. This increase during the last decade maybe a consequence of the need to understand the pathogenic model of dental erosion and the mechanisms involved to be able to easily interpret the findings found in research and in the everyday clinic. This will constitute the basis for the establishment of preventive and therapeutic measures $[15,16,26]$.

\section{Conclusions}

In order to answer the proposal objectives of this study, it could be concluded that there has been a significant increase in research articles on dental erosion in recent years, especially in Brazil and the UK, with a high number of translational articles in humans and cross-sectional observational studies. In addition, from the beginning of the study period until 2020, the number of signatories increased, as did international co-authorships, indicating a greater concern about dental erosion. This could be related to an increase in the societal awareness of healthy eating, since articles that relate to diet and erosion ranked second place, representing $23.4 \%$ of the publications. It also deserves to be highlighted that the number of female authors also continuously increased during the years of study.

Regarding the types of articles found, the gradual reduction in systematic reviews and meta-analyses that predominated during the first years of the study stands out, as does the increase in research studies over time.

These findings will help researchers, academics and students to characterize the most important aspects of dental erosion. In the same way, the need to establish a series of clinical practice guidelines for its management and prevention is evidenced.

Author Contributions: Conceptualization, L.M.M. and C.B.G.; methodology, L.M.M.; software, C.B.G.; validation, L.M.M., C.B.G. and E.G.M.; formal analysis, C.G.B.; investigation, P.B.G.; resources, C.G.B.; data curation, C.B.G.; writing-original draft preparation, L.M.M.; writing-review and editing, C.G.B. and P.B.G.; visualization, C.B.G.; supervision, E.G.M.; project administration, L.M.M. All authors have read and agreed to the published version of the manuscript.

Funding: This research received no external funding.

Institutional Review Board Statement: Not applicable.

Informed Consent Statement: Not applicable.

Conflicts of Interest: The authors declare no conflict of interest. 


\section{References}

1. Ganss, C. How valid are current diagnostic criteria for dental erosion? Clin. Oral Investig. 2008, 12, 41-49. [CrossRef]

2. Gandara, B.K.; Truelove, E.L. Diagnosis and management of dental erosion. J. Contemp. Dent. Pract. 1999, 1, 16-23. [CrossRef]

3. Bartlett, D. Etiology and prevention of acid erosion. Compend. Contin. Educ. Dent. 2009, 30, 616-620.

4. Imfeld, T. Dental erosion. Definition, classification and links. Eur. J. Oral Sci. 1996, 104, 151-155. [CrossRef]

5. Fajardo, M.C.; Mafla, A.C. Diagnóstico y epidemiología de erosión dental. Rev. Univ. Ind. Santander Salud 2011, 43, 179-189.

6. Lussi, A.; Hellwig, E. Erosive potential of oral care products. Caries Res. 2001, 35, 52-56. [CrossRef]

7. Esber, C.; Kagul, B.; Tanboga, I.; Lussi, A. Dental erosion among children in an Istanbul public school. J. Dent. Child. 2005, 72, 5-9.

8. Rabelo, M.A.; Reis, A.; Thiemi, M. Saliva and dental erosion. J. Appl. Oral Sci. 2012, 20, 493-502.

9. Campos, M.; Furtado, D.C.; Pedroso, C. Control of erosive tooth wear: Possibilities and rationale. Braz. Oral Res. 2009, $23,49-55$.

10. Lussi, A.; Schlueter, N.; Rakhmatullina, E.; Ganss, C. Dental erosion-an overview with emphasis on chemical and histopathological aspects. Caries Res. 2011, 45, 2-12. [CrossRef] [PubMed]

11. Shellis, R.P.; Ganss, C.; Ren, Y.; Zero, D.T.; Lussi, A. Methodology and models in erosion research: Discussion and conclusions. Caries Res. 2011, 45, 69-77. [CrossRef] [PubMed]

12. Huysmans, M.C.; Chew, H.P.; Ellwood, R.P. Clinical studies of dental erosion and erosive wear. Caries Res. 2011, 45, 60-68. [CrossRef]

13. Gupta, M.; Srivastava, N.; Gupnani, N. Dental erosion in children. J. Oral Health Community Dent. 2009, 3, 56-61.

14. Bartlett, D.W. The role of erosion in tooth wear: Etiology, prevention and management. Int. Dent. J. 2005, 55, 277-284. [CrossRef]

15. Milosevic, A.; Broside, D.A.; Slade, P.D. Dental erosion, oral hygiene and nutrition in eating disorders. Int. J. Eat. Disord. 1997, 21, 195-199. [CrossRef]

16. Marshall, T.A. Weak evidence suggests vegetarian diets may be associated with an increased risk of dental erosion. J. Evid. Based Dent. Pract. 2021, 21, 101524. [CrossRef]

17. Lussi, A.; Jaeggi, T. Erosion diagnosis and risk factors. Clin. Oral Investig. 2008, 12, 5-13. [CrossRef]

18. World Health Organization. Working for Health; WHO: Ginebra, Switzerland, 2006.

19. World Health Organization. 2008-2013 Action Plan for the Global Strategy for the Prevention and Control of Noncommunicable Diseases; WHO: Ginebra, Switzerland, 2008.

20. World Health Organization. The World Oral Health Report 2003; Oral Health Programme; WHO: Ginebra, Switzerland, 2003.

21. Naidoo, S.; Myburgh, N. Nutrition, oral health and the young child. Matern. Child Nutr. 2007, 3, 312-321. [CrossRef]

22. World Health Organization. International Statistical Classification of Diseases and Related Health Problems; 10th Revision; WHO: Ginebra, Switzerland, 2010.

23. Grimes, D.A.; Schulz, K.F. An overview of clinical research: The lay of the land. Lancet 2002, 5, 57-61. [CrossRef]

24. Struzycka, I.; Rusyan, E.; Boguslawska, A. Prevalence of dental erosion in young adults aged 18 years in Poland. Przeglad Epidemiol. 2014, 68, 689-693.

25. Costa, N.; Lima, A.C.; Torniziello, C.R.; Rosenblalt, A. Dental erosion and consumption of industrialized beverages in a group of children in Recife/Pernambuco, Brazil. Rev. Odonto Ciênc. 2009, 24, 120-123.

26. Hasselkvist, A.; Johansson, A.; Johansson, A.K. Dental erosion and soft drink consumtion in Swedish children and adolescents and the development of a simplified erosion partial recording system. Swed. Dent. J. 2010, 34, 187-195.

27. Nahas, M.S.; Correa, P.; Nahas, F.; Nahas, J.P.; Murakami, C.; Medeiros, F. Prevalence and associated factors of dental erosion in children and adolescents of a private dental practice. Int. J. Paediatr. Dent. 2011, 21, 451-458. [CrossRef] [PubMed]

28. Dugmore, C.R.; Rock, W.P. The progression of tooth erosion in a cohort of adolescents of mixed ethnicity. Int. J. Paediatr. Dent. 2003, 13, 295-303. [CrossRef]

29. Petrauskiene, Z. Bibliometric researches-New service at Vilnius University Library. ScieCom Info 2012, 8, 5-7.

30. Poskevicius, L.; Flor-Martínez, M.; Galindo-Moreno, P.; Juodzbalys, G. Scientific publications in dentistry in Lithuania, Latvia and Estonia between 1996 and 2018: A bibliometric analysis. Med. Sci. Monit. 2019, 25, 4414-4422. [CrossRef]

31. Patil, S.; Sarode, S.C.; Sarode, G.S.; Gadbail, A.R.; Gondivkar, S.; Kontham, U.R.; Alqahtani, K.M. A bibliometric analysis of the 100 most cited articles on early childhood caries. Int. J. Paediatr. Dent. 2020, 30, 527-535. [CrossRef]

32. Garcovich, D.; Marqués, L.; Adobes, M. Citation classics in paediatric dentistry: A bibliometric study on the 100 most-cited articles. Eur. Arch. Paediatr. Dent. 2020, 21, 249-261. [CrossRef]

33. Aura-Tormo, J.I.; García-Sanz, V.; Estrela, F.; Bellot-Arcis, C.; Paredes, V. Current trends in orthodontics journals listed in Journal Citation Reports. A bibliometric study. Am. J. Orthod. Dentofac. Orthop. 2019, 156, 663-674. [CrossRef]

34. Simon, L.; Candamo, F.; He, P.; Karhade, D.S.; Pirooz, Y.; Spinella, M.K.; Truong, M.K.; Wu, X.; Donoff, R.B. Gender differences in academic productivity and advancement among dental school faculty. J. Women's Health 2019, 28, 1350-1354. [CrossRef]

35. Steven, H. Writing in English for the Medical Sciences. A Practical Guide, 1st ed.; Broken Sound Parkway NW: Cambridge, UK, 2016; pp. 87-103. 